\title{
Two-phase modelling of nanofluid heat transfer in a microchannel heat sink
}

\author{
C. T. Nguyen ${ }^{1} \&$ M. Le Menn ${ }^{2}$ \\ ${ }^{I}$ Department of Mechanical Engineering, Faculty of Engineering, \\ Université de Moncton, Moncton, New Brunswick, Canada \\ ${ }^{2}$ UFRSSI Lorient, Université de Bretagne-Sud, Lorient, France
}

\begin{abstract}
The problem of a steady, two-dimensional, laminar forced flow and heat transfer of a nanofluid, Water- $\mathrm{Al}_{2} \mathrm{O}_{3}$ mixture, circulating inside a microchannel, $0.1 \mathrm{~mm}$ thickness by $25 \mathrm{~mm}$ length, was numerically studied. The nanofluid considered is composed of saturated water and alumina metallic particles with different average diameters, $36 \mathrm{~nm}$ and $47 \mathrm{~nm}$. All fluid properties are assumed temperature-dependent and evaluated using classical two-phase mixtures formulas, while for thermal conductivity and dynamic viscosity, recent in-house experimental data were used. The particle diffusion constant due to Brownian motion was estimated using the Einstein's relation. The fluid exhibits a parabolic axial velocity, uniform temperature and particle concentration profiles at the inlet; the usual non-slip and uniform wall temperature conditions prevail on both walls; at the exit, the 'outflow boundary' condition is imposed. The system of governing equations (conservation of mass, momentum, energy, and species) was successfully solved using a FEM imbedded within a commercial powerful code and a 28558-cell non-uniform grid. Results obtained for the Reynolds range of 200-2500 clearly show the beneficial effects due to the use of nanofluids on the heat transfer coefficient. Results using the two-phase model show that the spatial distribution of particle concentration is highly non uniform; it has been found to vary considerably in the vicinity of the heated walls while remains nearly uniform in a large central region of the channel. The effects due to the particle concentration and size were also studied. A 'single-phase fluid v/s twophase fluid model' comparison has clearly shown a certain discrepancy among the results obtained.

Keywords: microchannel, laminar forced flow, heat transfer, nanofluids, alumina-water nanofluid, two-phase fluid model, single-phase fluid model.
\end{abstract}




\section{Introduction}

Recent advances in manufacturing processes have permitted the fabrication of nanometre-scale solid particles, which, in turn, have created a new class of very special fluids, called 'nanofluids'. The latter refers to a two-phase composed of a continuous phase, most often a saturated liquid and suspended 'nanoparticles'. In spite of a striking lack of data, nanofluids appear to constitute a very interesting alternative for various thermal applications, especially those where high heat transfer rates are required. In fact, the capability of nanofluids for the heat transfer enhancement purpose has clearly been established for internal flow configurations - see in particular Pak and Cho [1], Li and Xuan [2], Wen and Ding [3], Yang et al. [4], Maïga et al. [5, 6]. A similar heat transfer enhancement was also observed experimentally for a closed-liquid system destined for cooling of high-powered electronic components, Roy et al. [7] and Nguyen et al. [8], as well as in cases of free convection (Polidori et al. [9]) and laminar mixed convection flow (Ben Mansour et al. [10-12] and Popa et al. [13]).

With regard to the fluid flow and heat transfer in microchannel, it is worth mentioning that such a topic has received in the past decades a special attention from researchers (reviews of relevant works may be found in Garimella and Sobhan [14], Morini [15], Steinke and Kandlikar [16] and Chen [18]). Unfortunately, there are few studies/data regarding nanofluid flow and heat transfer in microchannel. Faulkner et al. [19-20] were likely the first who experimentally found that surface heat fluxes in excess of $275 \mathrm{~W} / \mathrm{cm}^{2}$ may be achieved using ceramic-based nanoparticles in water. Koo and Kleinstreuer [21], in their numerical study, have observed that a combination of high-Pr fluid/high channel aspect ratio/high particle thermal conductivity would maximize the heat transfer rate. Chein and Huang [22], considering $\mathrm{Cu}$-nanoparticles-water, have clearly shown an improvement of heat transfer. Jang and Choi [23], taken into account the Brownian motion effect for $6 \mathrm{~nm}$ copper-in-water and $2 \mathrm{~nm}$ diamondin-water nanofluids, have shown that nanofluids reduce both the thermal resistance and temperature difference between the heated walls and the coolant. Tsai and Chein [24] performed an optimization study of a microchannel heat sink performance using copper-water and carbon-nanotube-water nanofluids. Chein and Chuang [25] studied experimentally $\mathrm{CuO}$-water nanofluid in a trapezoidalcross-section microchannel. They found that more heat can be absorbed using nanofluids for low flow rates, while for high flow rates, nanoparticles did not contribute to extra heat absorption. In a recent numerical study performed for a 3D-rectangular-cross-section microchannel, heat transfer enhancement was again observed for $\mathrm{Al}_{2} \mathrm{O}_{3}$-water and $\mathrm{CuO}$-water nanofluids (Nguyen et al. [26]).

In this work, we have numerically studied the problem of a forced laminar flow and heat transfer of $\mathrm{Al}_{2} \mathrm{O}_{3}$-water nanofluid, with two different particle sizes, $36 \mathrm{~nm}$ and $47 \mathrm{~nm}$, inside a two-dimensional flat microchannel. Both the singlephase fluid and two-phase fluid models were used. Some significant results showing the effects due to the use of nanofluid on the heat transfer coefficient as well as the comparison of between the two models are presented and discussed. 


\section{Mathematical formulation and numerical method}

\subsection{Governing equations and boundary conditions}

The problem under study consists of a steady, forced and laminar flow of a nanofluid flowing in a straight rectangular cross-section microchannel, Fig. 1, with dimensions, $\mathrm{a}=65 \mathrm{~mm}, \mathrm{e}=0.1 \mathrm{~mm}$ and length $\mathrm{L}=25 \mathrm{~mm}$. The nanofluid is assumed incompressible with temperature-dependent properties. The compression work is negligible, but both viscous dissipation as well as axial heat diffusion were considered. Because of the channel geometry and in order to reducing the computing times, it has been decided to consider a 2Dmicrochannel of $0.1 \mathrm{~mm}$ thickness and $25 \mathrm{~mm}$ of length. The general conservation equations of mass, momentum, energy and species are as follows (Eckert and Drake [26]):

$$
\begin{gathered}
\nabla \cdot(\rho \mathbf{V})=0 \\
\nabla \cdot\left(\rho \mathbf{V ~} \mathrm{V}_{\mathrm{i}}\right)=-\nabla \mathrm{P}+\nabla \cdot\left(\mu \nabla \mathrm{V}_{\mathrm{i}}\right) \\
\nabla \cdot\left(\rho \mathbf{V} \mathrm{C}_{\mathrm{p}} \mathrm{T}\right)=\nabla \cdot(\mathrm{k} \nabla \mathrm{T})+\Phi \\
\nabla \cdot(\mathbf{V} \mathrm{c})=\nabla \cdot(\mathbf{D} \nabla \mathrm{c})
\end{gathered}
$$

$\mathbf{V}, \mathrm{P}, \mathrm{T}$ are fluid velocity vector, pressure and temperature; $\mathrm{V}_{\mathrm{i}}$ is a velocity component; $\mathbf{c}$ and $\mathbf{D}$ are particle mass fraction and diffusion coefficient; $\Phi$ is the dissipation function; $\rho, \mu, \mathrm{k}, \mathrm{C}_{\mathrm{p}}$ are, respectively, fluid density, dynamic viscosity, thermal conductivity and specific heat, all properties are temperature-dependent.

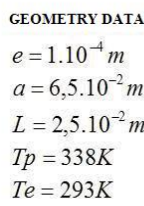

Figure 1: Geometry of the microchannel considered.

The non-linear and highly coupled governing equations (1-4) must appropriately be solved subject to the following boundary conditions: at the channel inlet, the fluid possesses a parabolic axial velocity profile, a uniform temperature and particle concentration profiles; at the outlet, the 'outflow boundary' condition (i.e. $\partial^{2} / \partial \mathrm{x}^{2}=0$ for all variables) is assumed. On the solid walls, a usual no-slip and uniform wall temperature conditions are specified.

\subsection{Nanofluid thermo-physical properties}

For the nanofluid considered, water- $\mathrm{Al}_{2} \mathrm{O}_{3}$ with $36 \mathrm{~nm}$ and $47 \mathrm{~nm}$ average particle-sizes, effective thermal and physical properties can be evaluated using 
classical formulas already derived and known for a two-phase fluid (subscripts $p$, bf and nf refer, respectively, to the particles, the base fluid and the nanofluid):

$$
\begin{gathered}
\rho_{\mathrm{nf}}=(1-\varphi) \cdot \rho_{\mathrm{bf}}+\varphi \rho_{\mathrm{p}} \\
\left(\rho \cdot C_{\mathrm{p}}\right)_{\mathrm{nf}}=(1-\varphi) \cdot\left(\rho \cdot \mathrm{C}_{\mathrm{p}}\right)_{\mathrm{bf}}+\varphi\left(\rho \cdot \mathrm{C}_{\mathrm{p}}\right)_{\mathrm{p}}
\end{gathered}
$$

For $\mathrm{Al}_{2} \mathrm{O}_{3}$ particles, the following data are used: $\mathrm{C}_{\mathrm{p}}=773 \mathrm{~J} / \mathrm{kg} \mathrm{K}$ and $\rho=3600$ and $3880 \mathrm{~kg} / \mathrm{m}^{3}$ for $36 \mathrm{~nm}$ and $47 \mathrm{~nm}$ sizes. For nanofluid thermal conductivity and dynamic viscosity, in-house experimental data, Angue Mintsa et al. [28] and Nguyen et al. [29], were used. These data are specific to the nanofluids studied. The diffusion coefficient $\mathbf{D}$ due to the particle Brownian motion was estimated using the following formula, often referred as the 'Einstein's relation', which relates the particle diffusion coefficient to the drag coefficient (see Berg [30] and Einstein [31]):

$$
\mathbf{D}(\mathrm{T})=\mathrm{k}_{\mathrm{B}} \mathrm{T} / \mathrm{k}_{\mathrm{drag}}=\mathrm{k}_{\mathrm{B}} \mathrm{T} /\left(6 \pi \mu \mathrm{R}_{\mathrm{p}}\right)
$$

where $\mathrm{k}_{\mathrm{B}}$ is the Boltzmann constant, $\mathrm{k}_{\mathrm{B}}=1.3806504 \times 10^{-23} \mathrm{~m}^{2} \mathrm{~kg} / \mathrm{s}^{2} \mathrm{~K}, \mu$ the mixture dynamic viscosity and $R_{p}$ the particle radius. Typical values of the coefficient $\mathbf{D}$ are ranging from 4 to $6 \times 10^{-12} \mathrm{~m}^{2} / \mathrm{s}$ for considered particles under ambient condition.

\subsection{Numerical method and code validation}

The system of governing equations (1)-(4) was successfully solved by using a 'finite-element' method embedded within a powerful commercial code named COMSOL Multiphysics. The matrixes resulting from the spatial discretization process have been solved using an efficient and iterative matrix decomposition technique. In order to ensure the accuracy and independence of results with respect to the number of elements used, several non-uniform grids were thoroughly probed and a 28558-quadratic-triangular-elements grid system was adopted. It covers the space of a half of the channel thickness and possesses very fine and highly packed elements near boundaries. The convergence was based on the verification of variables variation between iterations; and also on the global

\begin{tabular}{|c|c|c|c|c|c|}
\hline & & $\begin{array}{c}\text { Particle } \\
\text { fraction } \varphi\end{array}$ & & ynolds & \\
\hline \multirow{6}{*}{$\begin{array}{l}\text { Single-phase } \\
\text { fluid model }\end{array}$} & \multirow{3}{*}{$36 \mathrm{~nm}$} & $9 \%$ & \multirow{3}{*}{200} & \multirow{3}{*}{500} & \multirow{3}{*}{1000} \\
\hline & & $6 \%$ & & & \\
\hline & & $3.1 \%$ & & & \\
\hline & \multirow{3}{*}{$47 \mathrm{~nm}$} & $9 \%$ & \multirow{3}{*}{1500} & \multirow{3}{*}{2000} & \multirow{3}{*}{2500} \\
\hline & & $6 \%$ & & & \\
\hline & & $3.1 \%$ & & & \\
\hline \multirow{6}{*}{$\begin{array}{l}\text { Two-phase } \\
\text { fluid model }\end{array}$} & \multirow{3}{*}{$36 \mathrm{~nm}$} & $9 \%$ & \multirow{3}{*}{200} & \multirow{3}{*}{500} & \multirow{3}{*}{1000} \\
\hline & & $6 \%$ & & & \\
\hline & & $3.1 \%$ & & & \\
\hline & \multirow{3}{*}{$47 \mathrm{~nm}$} & $9 \%$ & \multirow{3}{*}{1500} & \multirow{3}{*}{2000} & \multirow{3}{*}{2500} \\
\hline & & $6 \%$ & & & \\
\hline & & $3.1 \%$ & & & \\
\hline \multirow{2}{*}{\multicolumn{2}{|c|}{ Water }} & \multirow{2}{*}{$0 \%$} & 200 & 500 & 1000 \\
\hline & & & 1500 & 2000 & 2500 \\
\hline
\end{tabular}
mass and energy balance over the domain, which was kept as low as $0.01 \%$.

Table 1: $\quad$ Summary of the cases studied. 
The computer model was successfully validated by comparing numerical results obtained for the axial velocity profile and pressure gradient to the wellknown and theoretical results for a classic case of a 2D-laminar forced Poiseuille flow in a channel (Le Menn [32]). The code was then used to perform nearly seventy-two cases for distilled water and the two nanofluids considered (Table 1).

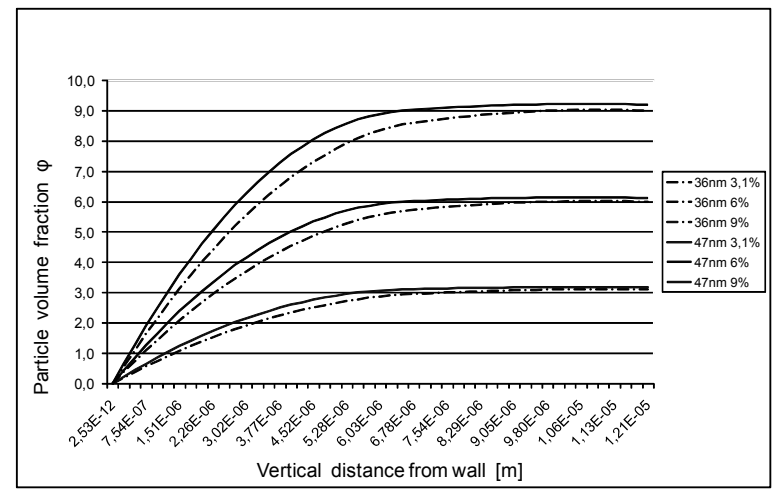

Figure 2: $\quad$ Spatial distribution of particle volume fraction $(\operatorname{Re}=200)$.

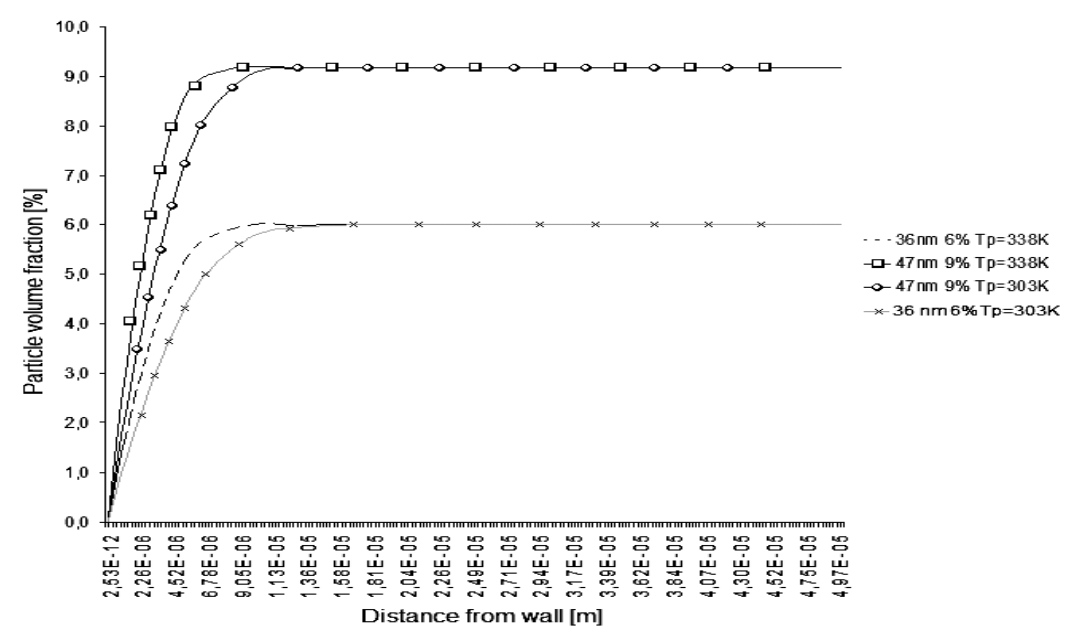

Figure 3: $\quad$ Effect of wall temperature on particle volume fraction profile.

\section{Results and discussion}

Some significant results as obtained by using the two-phase model are presented and discussed first, which is followed by a comparison between the single-phase and two-phase model. Figure 2 shows, for example, a (zoom view) typical spatial distribution of the particle volume fraction along a vertical distance to the wall for the case. It is observed that for a given particle volume fraction specified at 
the channel inlet, particle concentration clearly exhibits large variation in the vicinity of the wall, while in the central region of the channel, it remains almost constant.

For this case, the spatial variation of particle concentration is approximately observed within one-sixth of the channel half-thickness. It is also observed that $47 \mathrm{~nm}$ particle-size exhibits a slightly higher concentration gradient in the near wall region than particles of $36 \mathrm{~nm}$ size, which may appear somewhat paradoxical. It is worth noting that the particle concentration distribution is governed by the convection-diffusion process, hence it depends not only on the particle diffusion coefficient but on the local velocities and temperatures. Figure 3 also shows that for a given particle-size, higher wall temperatures would induce a higher gradient of the particle concentration near the solid wall. Such behaviour is obviously due to an increase of the particle diffusion coefficient with temperature augmentation.

\subsection{On the nanofluid heat transfer behaviour in a micro-channel}

From the results obtained and shown in Fig. 4, it is clear that the use of a nanofluid would produce an appreciable increase of heat transfer in a constantwall temperature microchannel heat sink, while compared to that when using water. In fact for a given particle-size, the average heat transfer coefficient ratio, $\mathrm{h}_{\text {nanofluid }} / \mathrm{h}_{\text {water }}$, is always higher than unity. This ratio clearly increases with the particle volume fraction. Thus, for the particle fractions considered, $3.1 \%, 6 \%$ and $9 \%$, this ratio has as values, respectively $1.55,2.1$ and 4.3 for $36 \mathrm{~nm}$ size and $1.5,2.25$ and 3.3 for $47 \mathrm{~nm}$ size. It is interesting to observe that such a ratio remains nearly constant for the range of the Reynolds number studied. Such a beneficial effect due to nanofluid can also be found on Fig. 5 which shows the variation of the average Nusselt number as function of Re, $\varphi$ and particle-size. One can see that the Nusselt number clearly increases with the increase of the Reynolds number (the convection effect) and with an increase of particle volume fraction. It may be expected that a combination of high Reynolds numbers and a high particle volume fraction can produce interesting heat transfer rates. There seems to be no clear demarcation between the $36 \mathrm{~nm}$ and $47 \mathrm{~nm}$ particle sizes regarding the heat transfer behaviour (it is worth noting that the definition of $\mathrm{Re}$ and $\mathrm{Nu}$ number also includes nanofluid properties). It is very interesting to mention that the above nanofluid heat transfer performance and behaviour appear consistent with that observed by others (see in particular Chen [18], Koo and Kleinstreuer [21], Chein and Chuang [25] and Nguyen et al. [26]).

\subsection{On the comparison 'single-phase v/s two-phase modelling'}

As mentioned previously, both the two-phase and single-phase fluid models were used in the present study. The results obtained from these models were compiled and compared in the following. Figure 6 shows, at first, the results for the ratio $\mathrm{h}_{\text {nanofluid }} / \mathrm{h}_{\text {water }}$ as function of Re for two particular cases (36nm and $\varphi=6 \%$ and $47 \mathrm{~nm}$ and $\varphi=9 \%$ ) using both models, considering, especially, all temperaturedependent properties. One can see that for the first case, $36 \mathrm{~nm}-6 \%$ particle 


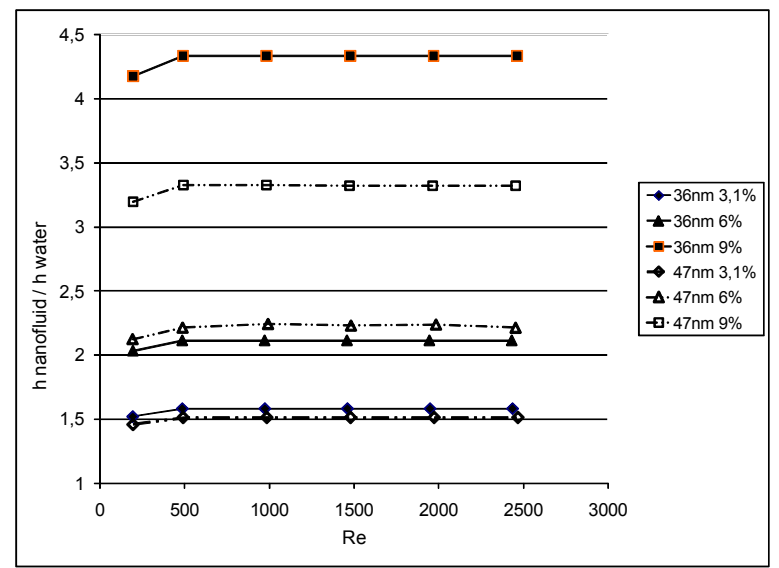

Figure 4: Variation of $h_{\text {nanofluid }} / h_{\text {water }}$ with respect to Re, $\varphi$ and particle-size.

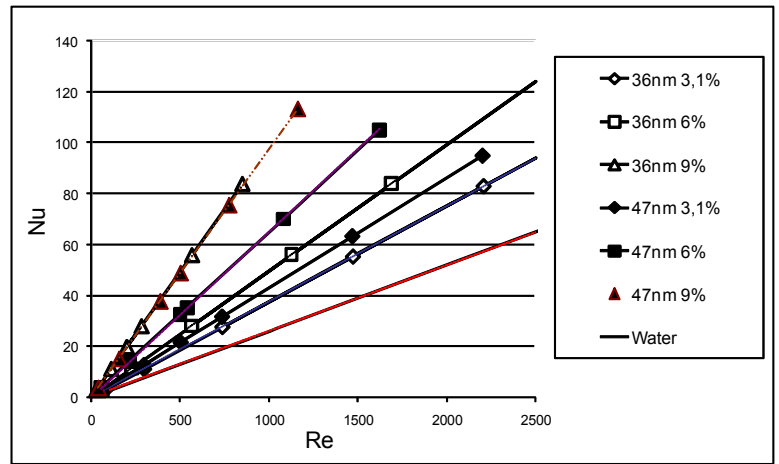

Figure 5: Variation of $\mathrm{Nu}$ with respect to $\mathrm{Re}, \varphi$ and particle-size.

volume fraction, there is a slight difference between the two models. However, for the second case, $47 \mathrm{~nm}-9 \%$ particle volume fraction, both models predict, surprisingly, approximately the same values for the ratio $h_{\text {nanofluid }} / h_{\text {water }}$.

Figure 7 shows finally the results for the average Nusselt number as function of parameter Re, results that are obtained using the single-phase fluid model (constant properties) and the two-phase model (variable properties). These results eloquently show that, on the global basis, there is a notable discrepancy between the predictions by the two models. Such a discrepancy, which does exist for all Reynolds number considered, becomes more pronounced for higher values of the latter. For the cases studied, it has been found that such a discrepancy appears to be more important for the case 6\%-36nm particle-size than the one with $9 \%-47 \mathrm{~nm}$-size. Although we may expect that the results obtained using the two-phase-variable-properties fluid model would be more realistic than the ones using the simple single-phase-constant-properties model, it is obvious that more results and experimental data will indeed be needed to validate such a result. 


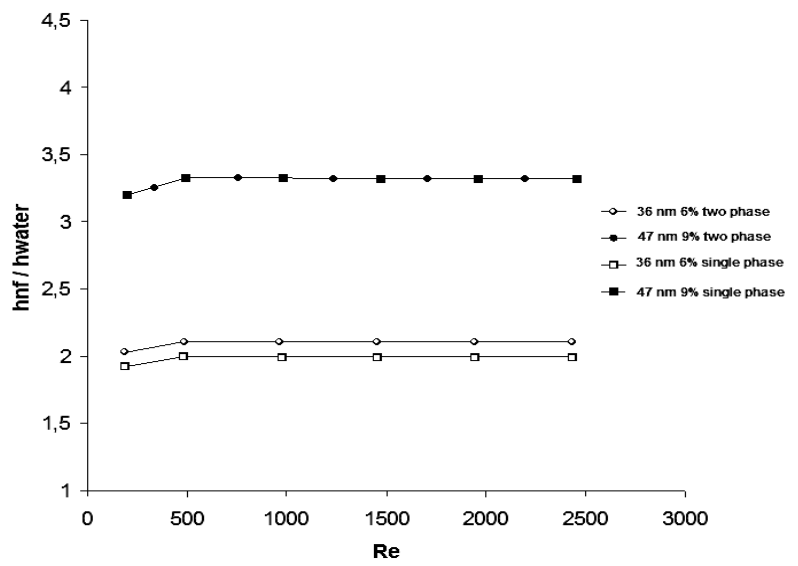

Figure 6: $\quad h_{\text {nanofluid }} / h_{\text {water }}$ function of Re (two-phase vs. single-phase model).

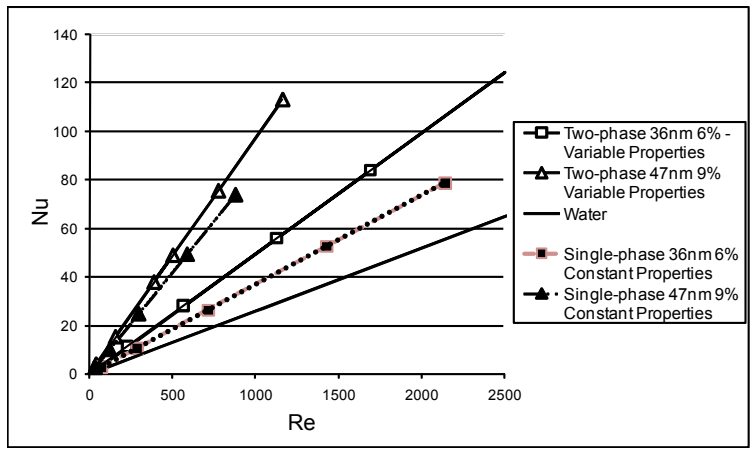

Figure 7: $\quad \mathrm{Nu}$ function of Re (two-phase vs. single-phase model).

\section{Conclusion}

In this paper, the problem of the laminar forced convection of $\mathrm{Al}_{2} \mathrm{O}_{3}$-water nanofluids inside a constant-wall-temperature two-dimensional microchannel has been numerically investigated. Both the single-phase and two-phase fluid models were used. Results have shown that the particle concentration exhibits a large spatial variation in the vicinity of solid wall, while it remains almost constant in the central area of the channel. The wall heat transfer has been found to increase appreciably with an increase of the flow Reynolds number and the particle volume fraction. There is a clear discrepancy between results predicted by the variable-property-two-phase fluid model and those using the conventional constant-property-single-phase fluid model.

\section{Acknowledgements}

We wish to thank the Natural Sciences and Engineering Research Council of Canada for financial support to this work and the Université de Bretagne-Sud (France) for granting a financial aid to Mr. Le Menn. 


\section{References}

[1] Pak, B. C. and Cho, Y. I., Hydrodynamic and heat transfer study of dispersed fluids with submicron metallic oxide particles. Exp. Heat Transfer, 11(2), pp. 151-170, 1989.

[2] Li, Q., Xuan, Y., Convective heat transfer performances of fluids with nano-particles. Proc. $12^{\text {th }}$ Int. Heat Transfer Conference, Grenoble, France, pp. 483-488, 2002.

[3] Wen, D., Ding, Y., Experimental investigation into convective heat transfer of nanofluids at the entrance region under laminar flow conditions. Int. J. Heat Mass Transfer, 47, pp. 5181-5188, 2004.

[4] Yang, Y, Zhang, Z.G., Grulke, E.A., Anderson, W.B. and Wu, G., Heat transfer properties of nanoparticle-in-fluid dispersions (nanofluids) in laminar flow. Int. J. Heat Mass Transfer, 48(6), pp. 1107-1116, 2005.

[5] Maïga, S. E. B., Palm, S. J., Nguyen, C. T., Roy, G., Galanis, N., Heat transfer enhancement by using nanofluids in forced convection flows. Int. J. Heat Fluid Flow, 26, pp. 530-546, 2005.

[6] Maïga, S.E.B., C. T. Nguyen, N. Galanis, G. Roy, T. Maré, Coqueux, M., Heat transfer enhancement in turbulent tube flow using $\mathrm{Al}_{2} \mathrm{O}_{3}$ nanoparticle suspension. Int. J. Num. Meth. Heat Fluid Flow, 16(3), pp. 275-292, 2006.

[7] Roy, G., C. T. Nguyen, Comeau, M., Numerical investigation of electronic component Cooling enhancement using nanofluids in a radial flow cooling system. J. Enhanced Heat Transfer, 13(2), pp. 101-115, 2006.

[8] Nguyen, C. T., G. Roy, C. Gauthier, Galanis, N., Heat transfer enhancement using $\mathrm{Al}_{2} \mathrm{O}_{3}$ water nanofluid for an electronic liquid cooling system. Applied Thermal Engineering, 27(8-9), pp. 1501-1506, 2007.

[9] Polidori, G., S. Fohanno, Nguyen, C. T., A note on heat transfer modeling of Newtonian nanofluids in laminar free convection. Int. J. Thermal Sciences, 46, pp. 739-744, 2007.

[10] Ben Mansour, R., N. Galanis, Nguyen, C.T., Developing laminar mixed convection of nanofluids in a horizontal tube with uniform wall heat flux. Proc. $13^{\text {th }}$ IHTC, Sydney NSW, Australia, Begell House, ISBN-1-56700-2269 (on CD), 2006.

[11] Ben Mansour, R., N. Galanis, C.T. Nguyen, Aouina, C., Experimental study of mixed convection laminar flow of water- $\mathrm{Al}_{2} \mathrm{O}_{3}$ nanofluid in horizontal tube. Proc. 5th IASME/WSEAS Int. Conf. Heat Trans., Therm. Eng. Envir., Vouliagmeni (Greece), pp. 193-197, 2007.

[12] Ben Mansour, R., N. Galanis, Nguyen, C.T., Developing laminar mixed convection of nanofluids in an inclined tube with uniform wall heat flux. Int. $J$. Num. Methods Heat Fluid Flow (in press), 2008.

[13] Popa, C.V, S. Fohanno, G. Polidori, C.T. Nguyen, Heat transfer enhancement in mixed convection using water- $\mathrm{Al}_{2} \mathrm{O}_{3}$ nanofluid. Proc. 5th Euro. Therm. Sci. Conf., Eindhoven (Netherlands), Paper No. MCV-4, 8p, 2008.

[14] Garimella, S. and Sobhan, C., Transport in Microchannels - A Critical Review. Annual Review of Heat Transfer, 13, pp. 1-50, 2003. 
[15] Morini, G. L., Single-phase convective heat transfer in microchannels: a review of experimental results. Int. J. Thermal Sci., 43, pp. 631-651, 2004.

[16] Steinke, M. E., Kandlikar, S.G., Single-phase liquid friction factors in

[17] Microchannels. Int. J. Thermal Sci., 45, pp. 1073-1083, 2006.

[18] Chen, C. -H., Forced convection heat transfer in microchannel heat sinks. Int. J. Heat Mass Transfer, 50, pp. 2182-2189, 2007.

[19] Faulkner, D. J., Khotan, M., Shekarriz, R., Practical design of a $1000 \mathrm{~W} / \mathrm{cm}^{2}$ cooling system. Proc. 19 $9^{\text {th }}$ Ann. IEEE SemiTherm Symp., pp. 223-230, 2003.

[20] Faulkner, D. J., Shekarriz, R., Forced convective boiling in microchannels for $\mathrm{kW} / \mathrm{cm}^{2}$ electronics cooling. HT2003, ASME Summer Heat Transfer Conf., Las Vegas, Nevada, USA, pp. 329-336, 2003.

[21] Koo, J. and Kleinstreuer, C., Laminar nanofluid flow in microheat-sinks. Int. J. Heat Mass Transfer, 48, pp. 2652- 2661, 2005.

[22] Chein, R., Huang, G., Analysis of microchannel heat sink performance using nanofluids. Applied Thermal Engng., 25, pp. 3104-3114, 2005.

[23] Jang, S. P., Choi, S. U. S., Cooling performance of a microchannel heat sink with nanofluids. Applied Thermal Engng., 26, pp. 2457-2463, 2006.

[24] Tsai, T.-H., Chein, R., Performance analysis of nanofluid-cooled microchannel heat sinks. Int. J. Heat Fluid Flow, 28(5), pp.1013-1026, 2007.

[25] Chein, R., Chuang, J., Experimental microchannel heat sink performance studies using nanofluids. Int. J. Thermal Sci., 46, pp. 57-66, 2007.

[26] Nguyen, C.T., M. Jarrahi Khameneh, N. Galanis, Laminar forced and heat transfer enhancement by using water-based nanofluids in a microchannel. Proc. ICHMT Int. Symp. Advances in Computational Heat Transfer, Marrakech, Morocco, Paper No. CHT-08-106, 19p (CD), 2008.

[27] Eckert, E.R.G., Drake, R.M., Jr., Analysis of heat and mass transfer, McGrawHill Book Co., New York, NY, USA, 1972.

[28] Angue Mintsa, H., G. Roy, C.T. Nguyen, D. Doucet, New temperaturedependent thermal conductivity data for water-based nanofluids. Int. J. Therm. Sci., 49, pp. 363-371, 2009.

[29] Nguyen, C. T., F. Desgranges, G. Roy, N. Galanis, T. Maré, S. Boucher, H. A. Mintsa, H. A., Temperature and particle-size dependent viscosity data for water-based nanofluids-Hysteresis phenomenon. Int. J. Heat Fluid Flow, 28(6), pp. 1492-1506, 2007.

[30] Berg, H. C., A random walk in biology, Princeton University Press, 152p, 1993.

[31] Einstein, A., Investigations on the Theory of the Brownian Movement, Eds. R. Fürth \& A.D. Cowper, Courier Dover Publications, USA, 122p, 1956.

[32] Le Menn, M., Modélisation diphasique de l'écoulement laminaire de nanofluides dans un microcanal, Rpt., 38p, Department of Mechanical Engineering, Faculty of Engineering, Université de Moncton, Moncton, NB, Canada, June 2008. 